\title{
Virtual Shadowing Program for Preclinical Medical Students
}

\author{
Prashant Saini ${ }^{1} \cdot$ Kunal Debroy $^{2} \cdot$ Christopher Badger $^{1} \cdot$ Cynthia Powell $^{1} \cdot$ Punam Thakkar $^{1} \cdot$ Katherine C. Chretien $^{1}$ C
}

Accepted: 8 June 2021 / Published online: 16 June 2021

(c) This is a U.S. government work and not under copyright protection in the U.S.; foreign copyright protection may apply 2021

\begin{abstract}
Our annual summer shadowing program for preclinical medical students faced significant challenges due to COVID-19-related safety and resource concerns during Summer 2020. We created a pilot 7-week virtual shadowing program with the goal of providing virtual observational clinical experiences to increase students' clinical exposure and understanding of medical specialties. Faculty and preclinical medical students were matched via student preference selection and mentor availability. A practice guide was developed that outlined suggested virtual shadowing procedures. Afterward, participating faculty and students were surveyed on their experience. Overall, both faculty and students found the program effective and experienced limited technological difficulty.
\end{abstract}

Keywords Virtual $\cdot$ Shadowing $\cdot$ COVID $\cdot$ Preclinical $\cdot$ Specialty choice

\section{Background}

In Spring 2020, medical schools were forced to modify their curricula due to the COVID-19 pandemic, most halting inperson clinical rotations and direct patient contact for weeks to months [1]. While much of the concern surrounding the impact of the pandemic on medical education has focused on third- and fourth-year clerkships [2], the pandemic's impact on preclinical students has not been well explored. In particular, in-person shadowing during the preclinical years can facilitate specialty career choice and enhanced clinical skills. Studies have shown that early patient contact in medical training has positive impacts on students' comfort with clinical settings and patient care [3, 4]. Students who shadow are able to give context to their training early and are motivated to learn more in the classroom [3]; they also self-report improved medical knowledge, improved quality of interactions with other health professionals and patients, and improved history and physical examination skills [5]. Furthermore, early exposure to different clinical

Katherine C. Chretien

kchretie@gwu.edu

1 The George Washington University School of Medicine and Health Sciences, Washington, DC, USA

2 Hershey Medical Center, Penn State University, Hershey, PA, USA settings through shadowing experiences may allow students to explore and form decisions about future specialty choice $[6,7]$.

At George Washington University School of Medicine and Health Sciences, we host an annual voluntary summer shadowing program for medical students between years 1 and 2 for the aforementioned benefits. However, the pandemic introduced challenges of student safety, availability of PPE, limited faculty availability, physical distancing needs, and increased telehealth visits. In response, we created a virtual shadowing program with the goal of providing virtual observational clinical experiences to increase preclinical students' clinical exposure and understanding of medical specialties and assessed student and faculty feasibility, acceptability, and experiences.

\section{Activity}

Our pilot, 7-week virtual shadowing program took place from June to August 2020. In May 2020, full-time faculties were recruited to participate through the faculty listserv and were asked to list their availability and preferences for number of students they could precept. No interested faculty members were excluded. Subsequently, all first-year students were notified about the virtual shadowing program with a list of available faculty preceptors. Interested students were matched to faculty preceptors based on student-provided preferences. A best practice guide was developed and distributed to 
preceptors that listed recommended process steps, after no other such resources were found upon literature and internet searches. Two models were provided for virtual interactions: one allowing the student to join in on an existing telemedicine encounter and one model for virtually including students during in-person clinic visits. Most preceptors were matched with multiple students. Scheduling of shadowing sessions was left to the discretion of student and preceptor. Most providers at our institution used Zoom for telehealth visits. For surgical specialties, students only shadowed during clinic days; we were unable to support virtual operating room access.

Upon conclusion of the shadowing program, students and faculty were surveyed electronically to evaluate the effectiveness of the program and to elicit improvements. Survey contents were piloted by both students and faculty and included questions about program logistics, suggestions for improvement, and student participation and engagement with the program.

We analyzed survey data using descriptive statistics. Free-text analysis was performed for open-ended comments via an inductive approach that utilized comment content to drive coding and thematic development, a similar approach to one used by Cunningham and Wells [8]. The comments were initially divided into two categories: student and faculty responses. Second-order coding involved organizing comments into themes of positive and negative. Lastly, thirdorder coding was based on the content of the comment itself.

Themes were created based on the subjects being addressed (e.g., comments about the students/preceptors or comments about the program itself). Finally, subthemes were created from identifying patterns in each theme. For example, for "positive qualities of students," student engagement was mentioned in six comments and was identified as a subtheme. A representative comment was selected for each subtheme. Coding discrepancies were resolved through discussion. This study was considered exempt from review by the George Washington University Institutional Review Board.

\section{Results/Discussion}

Forty-eight (48) students and 22 faculty participated, of which 26/48 (54\%) students and 13/22 (59\%) faculty completed surveys. Faculty represented a spectrum of specialties, from primary care to subspecialty surgery. See Table 1 for respondent characteristics and selected results. Most faculty respondents $(61 \%)$ were matched with two students. The majority of responding students (58\%) shadowed faculty 5 or more times over the course of the program, while $19 \%$ shadowed 3-4 times. Many students participated remotely while outside of the local school region $(12 / 26 ; 46 \%)$. On a 5 -point Likert scale, $81 \%$ strongly agreed with the statement "I enjoyed the shadowing experience," while the remaining respondents agreed. Ninety-two percent of students agreed or strongly agreed that they were engaged with shadowing and $92 \%$ agreed or strongly agreed that they gained increased knowledge of their preceptor's specialty. All but one student (96\%) agreed that they would recommend the program to a peer, while the remaining student was neutral. Most faculty respondents (77\%) agreed that they would participate in the program again. Both faculty and students experienced limited technological difficulties.

Free-text analysis of positive comments from students (Fig. 1) revealed positive assessment of their preceptors and the program. Students appreciated the mentorship aspect of the program. Most students had positive comments for their preceptors and felt that an active effort was made to engage and teach them during patient encounters. When it came to the program itself, free-text analysis showed exposure to different specialties as the most common benefit. We also performed a free-text analysis for suggestions for improvement by students (Fig. 1). These suggestions primarily focused on suggestions for the preceptors, mainly through increasing student preparation by providing educational resources and access to electronic medical records prior to shadowing. Some students also commented on improvements that could be made to the program logistics, like improved communication by faculty with students and expansion of the number of participating faculty.

Free-text analysis of faculty responses (Fig. 2) showed that the most consistent praise was high levels of student engagement. Other faculty members praised the virtual shadowing format, noting that it made it easier to teach students and coordinate multiple students shadowing. Faculty suggestions for improvement (Fig. 2) noted unprofessionalism in the students who shadowed them and commented on logistical improvements that could be made to the program.

Overall, our virtual shadowing program that was created out of necessity due to the COVID-19 pandemic was well received by both students and faculty and accomplished our goals of providing clinical exposure to preclinical students and increased understanding of medical specialties. We were surprised by how many faculty members were willing to try the virtual format and the rarity of technological difficulties encountered by both students and faculty. While we did not specifically ask faculty whether they participated using established telemedicine visits versus streaming in-person visits, it appears that the faculty primarily chose to use telemedicine visits. Most students participated in 5 or more shadowing sessions during the program, and we believe that 
Table 1 Student and faculty respondent characteristics and selected results

\begin{tabular}{|c|c|}
\hline Student respondents $(N=26)$ & $\mathrm{n}(\%)$ \\
\hline \multicolumn{2}{|l|}{ Gender } \\
\hline Female & $19(61.5)$ \\
\hline Male & $7(26.9)$ \\
\hline \multicolumn{2}{|l|}{ Age } \\
\hline$<25$ & $21(80.7)$ \\
\hline $25-29$ & $5(19.2)$ \\
\hline \multicolumn{2}{|l|}{ Number of sessions shadowed } \\
\hline 2 or less & $6(23.1)$ \\
\hline $3-4$ & $5(19.2)$ \\
\hline 5 or more & $15(57.7)$ \\
\hline \multicolumn{2}{|l|}{ Physical location } \\
\hline Local & $14(53.8)$ \\
\hline Remote & $12(46.2)$ \\
\hline \multicolumn{2}{|l|}{ Agreement with the following statements (agree or strongly agree): } \\
\hline I enjoyed the shadowing experience & $26(100.0)$ \\
\hline I felt engaged by the shadowing experience & $24(92.3)$ \\
\hline As a result of this experience, my understanding of my preceptor's specialty has increased & $24(92.3)$ \\
\hline I would recommend this experience to other students in the future & $25(96.1)$ \\
\hline The technology was easy to use & $23(88.5)$ \\
\hline \multicolumn{2}{|l|}{ Faculty respondents $(N=13)$} \\
\hline \multicolumn{2}{|l|}{ Gender } \\
\hline Female & $7(53.8)$ \\
\hline Male & $6(46.2)$ \\
\hline \multicolumn{2}{|l|}{ Age } \\
\hline $25-34$ & $3(23.1)$ \\
\hline $35-44$ & $4(30.8)$ \\
\hline $45-60$ & $4(30.8)$ \\
\hline$>60$ & $2(15.4)$ \\
\hline \multicolumn{2}{|l|}{ Telehealth sessions per week } \\
\hline $0-1$ & $3(23.1)$ \\
\hline $1-2$ & $6(46.1)$ \\
\hline $3-4$ & $4(30.8)$ \\
\hline \multicolumn{2}{|l|}{ Agreement with the following statements (agree or strongly agree): } \\
\hline I would participate in the virtual shadowing program in the future & $10(76.9)$ \\
\hline The technology was easy to use & $12(92.3)$ \\
\hline
\end{tabular}

the flexibility of the program led to this high participation rate.

The flexibility and accessibility of the program are made more salient by the survey results showing that over $50 \%$ of students were outside of the DC metropolitan area. In addition, time is an often-cited barrier to clinical teaching in medical schools; some faculty reported having increased time for teaching during virtual sessions compared to typical in-person clinic sessions.

Limitations of this educational innovation include the relatively small numbers of participating students and faculty. Our faculty mainly used the video conferencing platform Zoom; results may not be generalizable to other platforms. Some comments from students and faculty suggested that better expectation setting was needed for both parties. Additional recruitment of faculty may allow for more individualized, in-depth experiences for students.

In sum, we found that virtual shadowing can be used to expand preclinical students' access to clinical observational experiences, allowing for meaningful, flexible, and remote learner participation. 


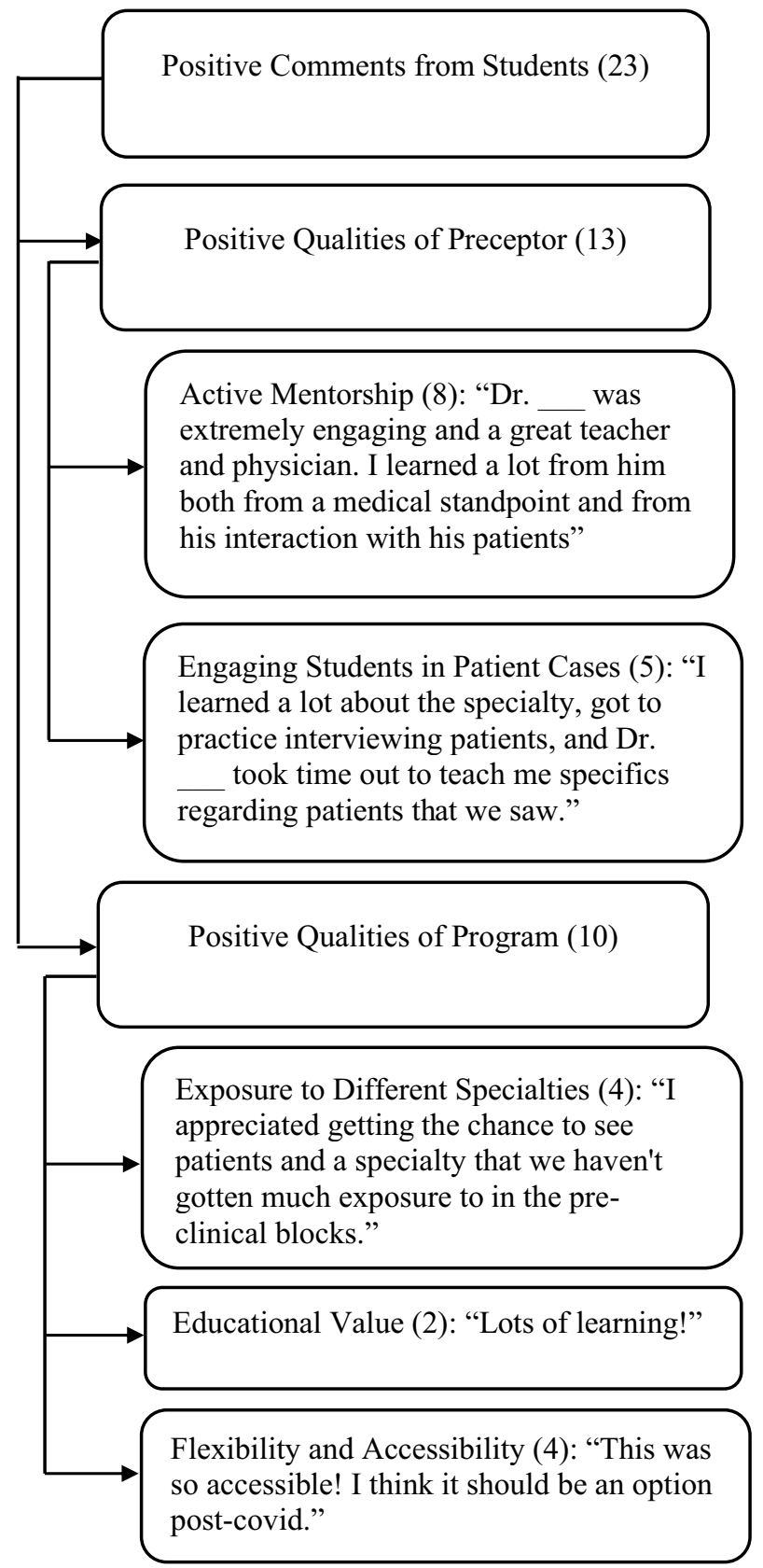

Fig. 1 A free-text analysis of positive and critical feedback by students

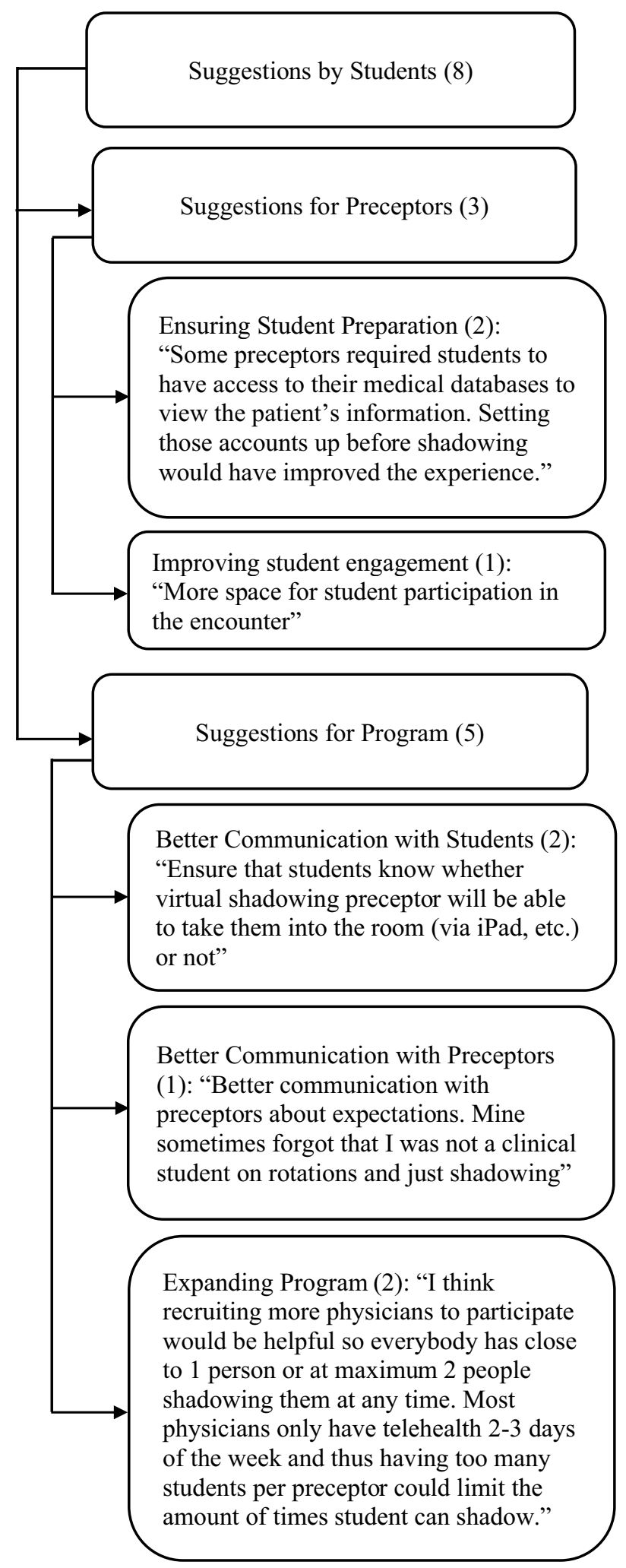



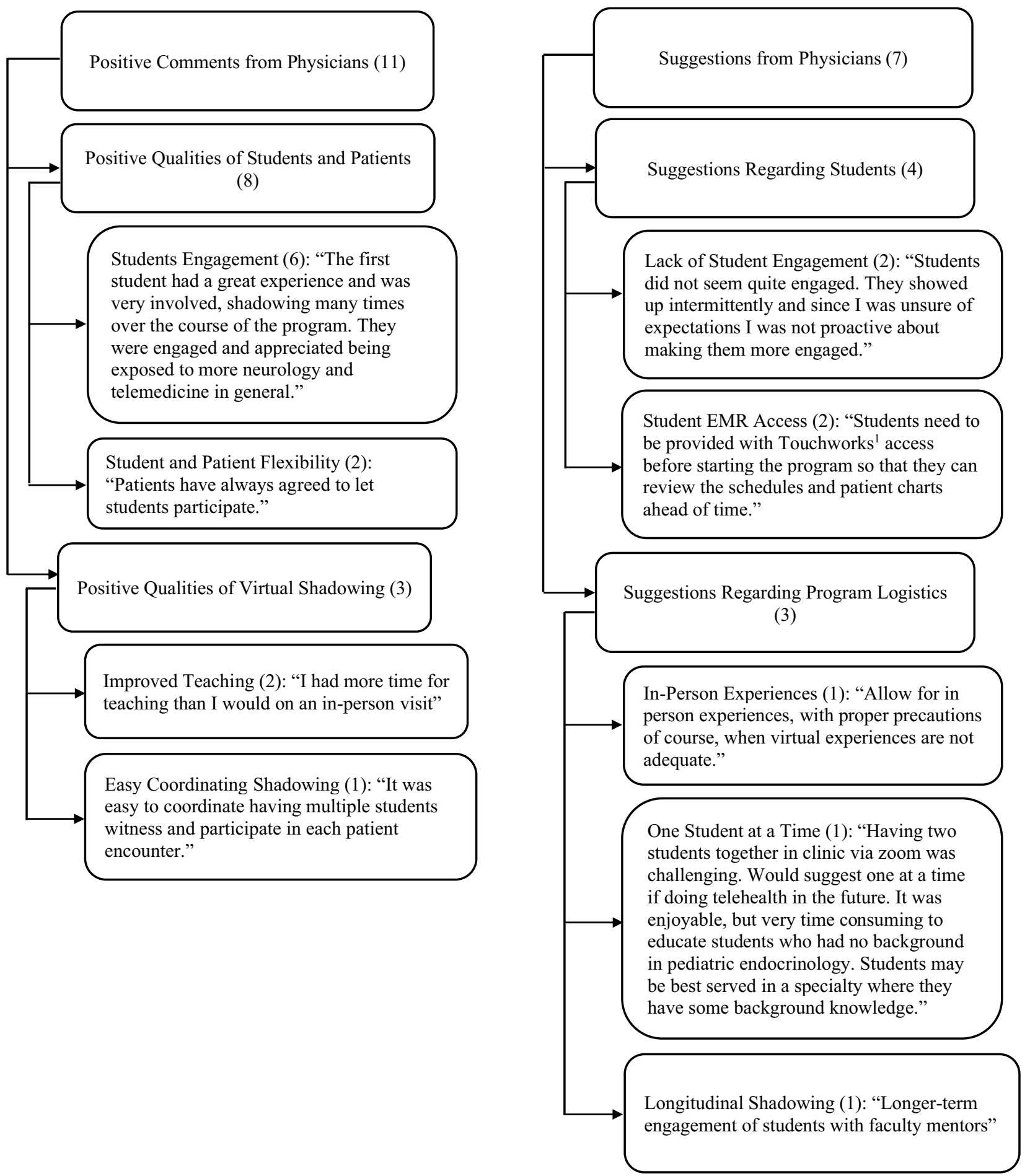

Fig. 2 A free-text analysis of positive and critical feedback by physician preceptors. (1) Touchworks are an electronic medical record (EMR) system 


\section{Declarations}

Ethics Approval This study was considered exempt from review by the George Washington University Institutional Review Board.

Conflict of Interest The authors declare no competing interests.

\section{References}

1. Association of American Medical Colleges. Interim guidance on medical students' voluntary participation in direct patient contact activities: principles and guidelines [Press release]. 2020. Retrieved from https://lcme.org/wp-content/uploads/filebase/ March-23-2020-Interim-Guidance-on-Medical-StudentsE28099Voluntary-Participation-in-Direct-Patient-Contact-Activities.pdf.

2. Rose S. Medical student education in the time of COVID-19. JAMA. 2020;323(21):2131-2.

3. Wenrich MD, Jackson MB, Wolfhagen I, Ramsey PG, Scherpbier AJJ. What are the benefits of early patient contact?-A comparison of three preclinical patient contact settings. BMC Med Educ. 2013;13:80.
4. Dornan T, Littlewood S, Margolis SA, Scherpbier A, Spencer J, Ypinazar V. How can experience in clinical and community settings contribute to early medical education? A BEME systematic review. Med Teach. 2006;28(1):3-18.

5. Turner SR, White J, Poth C, Rogers WT. Preparing students for clerkship: a resident shadowing program. Acad Med. 2012;87(9):1288-91.

6. Dotters-Katz S, Panzer A, Givens M, Smid M, Chuang A. Preclinical labor-and-delivery shadowing: the impact on medical students' perceptions of obstetrics and gynecology. AJP Rep. 2018;8(2): $64-7$.

7. Allen JG, Weiss ES, Patel ND, et al. Inspiring medical students to pursue surgical careers: outcomes from our cardiothoracic surgery research program. Ann Thorac Surg. 2009;87(6):1816-9.

8. Cunningham M, Wells M. Qualitative analysis of 6961 free-text comments from the first National Cancer Patient Experience Survey in Scotland. BMJ Open. 2017;7(6): e015726. https://doi. org/10.1136/bmjopen-2016-015726.PMID:28619780;PMCID: PMC5734250.

Publisher's Note Springer Nature remains neutral with regard to jurisdictional claims in published maps and institutional affiliations. 